\title{
SOME TESTS OF STEEL-WIRE ROPE ON SHEAVES.
}

\author{
By Edward Skillman.
}

ABSTRACT.

Tests of wire rope $5 / 8,3 / 4,7 / 8, I$, and $\mathrm{I} / 4$ inches in diameter were made on sheaves of Io, I4, and 18 inch diameter to determine their strength under static load. The ropes were all of 6-strand, I9-wire construction made from "plow" steel. It was found that the strength on sheaves was less than that of the straight ropes, the ratio of the strengths being 0.87 for $5 / 8$-inch rope on Io-inch sheaves and 0.95 on 18 -inch sheaves; for $\mathrm{I} / 4$-inch rope the corresponding values were 0.76 and 0.85 .

The tensile strength of individual wires was about $230,000 \mathrm{lbs}$./in. ${ }^{2}$, elongation in 8 inches about 2 per cent, and reduction of area about 46 per cent. These were practically the same for all sizes of wire. The strength of the straight ropes followed closely the equation $S=83,000 d^{2}$, in which $S$ is the strength in pounds and $d$ the diameter of the rope in inches. One worn rope which was tested showed a surprisingly high strength when its condition is considered.

A point of inflection in the load diagrams was found at from 56 to 65 per cent of the ultimate load, above which the elongation increased rapidly. The elongation of straight rope over a gage length of about 40 inches was about 2.5 per cent and the reduction of diameter about 4 per cent. The modulus of elasticity of a new rope was about $8,500,000 \mathrm{lbs}$. $/ \mathrm{in}^{2}$ and of worn rope about $\mathrm{I}_{3}, 500,000 \mathrm{lbs}$./in. ${ }^{2}$.

\section{CONTENTS.}

I. General scope and purpose of tests.

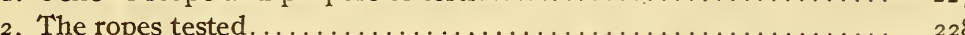

II. Description of the tests . . . . . . . . . . . . . . . .

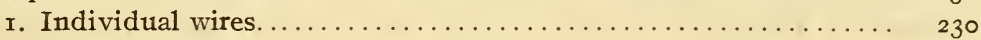

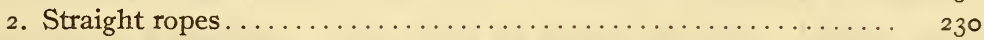

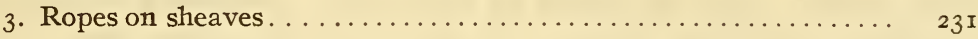

III. Results of the tests. . . . . . . . . . . .

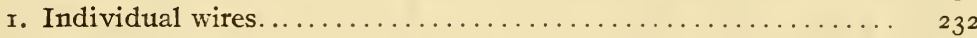

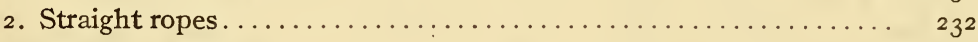

3. Ropes on sheaves. . . . . . . . . . . . . . . . . . . 239

IV. Conclusions. ................................. 240

\section{INTRODUCTION.}

\section{GENERAL SCOPE AND PURPOSE OF TESTS.}

It is the custom in engineering practice to determine the strength of wire rope by tests in tension. These tests are usually sufficient to furnish data as to the comparative strengths, qualities, and behaviors of the materials. They serve as the basis for acceptance 
or rejection in purchase specifications. On the other hand, it is frequently desirable to investigate the behavior of a material in a manner simulating, as nearly as practicable, those conditions under which it is ordinarily used. Data of this character are comparatively meager in the case of wire rope.

The tests described here were made at the request of the American Bridge Co., erection department. This company uses many wire ropes in general construction and erecting work. Information was desired as to their behavior when used upon sheaves of various diameters, and more particularly as to their strength when used for the hoisting blocks of cranes and derricks. It is clear that a number of independent variables may be studied in an investigation of this problem. On the other hand, it seemed advisable, for practical purposes, to limit the tests to static loads. It was decided that the behavior of a continuously wound rope in a block and tackle of many sheaves and "fall" lines could be sufficiently approximated, for test purposes, by the employment of a single continuous loop over two sheaves, thus saving unnecessary expense and simplifying the interpretation of the test results.

\section{THE ROPES TESTED.}

The ropes tested were known commercially as "plow steel wire hoisting ropes." Their diameters were $5 / 8,3 / 4,7 / 8, \mathrm{I}$, and $\mathrm{I} 1 / 4$ inches. Except for one sample the ropes were in the condition in which they left the factory, except that they had been exposed to moisture during storage, which had caused some of the outside wires to rust in spots. However, in general, the lubricant had preserved them very well. The only other imperfections found were slight cuts on some of the wires, probably made by the machines used for laying the wires in the rope, and imperfect welds where the wires had been lengthened. These flaws could be found only by very close inspection or by testing, so that the ropes would probably be classed commercially as "perfect."

One rope had been in service for five years and had been used to lift loads of from 5 to 50 tons on a steel derrick car, where a continuous rope, passing over a number of sheaves, formed is parallel lines. This rope, exposed to the weather, had been lubricated at intervals of two or three months with a paste of equal parts of flake graphite and "600-W" cylinder oil. When received at the laboratory, however, very little lubricant could be observed on it. The rope core was nearly free from lubricant. 
The outer wires had been worn by the sheaves and by slipping on each other to a depth of about one-half of their radii. Many of the wires were broken. For uniformity, all test pieces of each kind and size were cut from one rope having a length of abour 100 feet.

The chemical composition of the steel, the nature of the rope core, and the character of the lubricant used on the rope were determined. They are, in general agreement with the results obtained in the tests of wire ropes, described in Bureau of Standards Technologic Paper No. I2I. The carbon content was found to be from 0.64 to 0.70 of I per cent, with the exception of three-

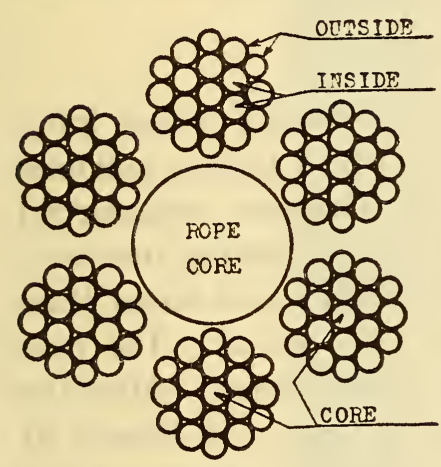

NEW ROPES

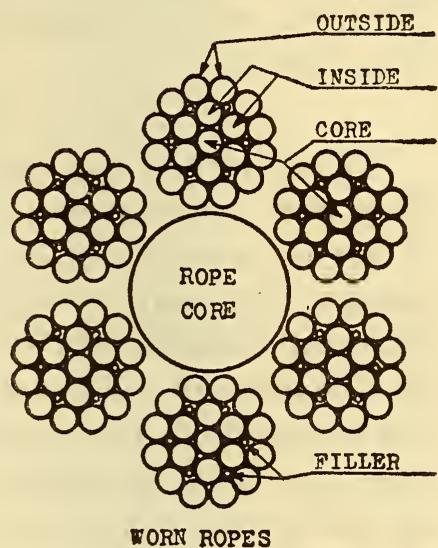

WORN ROPES

Fig. I. The construction of new and worn ropes.

fourths inch worn rope, which had 0.38 per cent carbon. The rope core was made of jute or manila fiber and lubricated by mineral oil.

The construction of the new and of the worn ropes is shown in Figure I. The construction of the worn specimens is similar to that of the new ones, with the exception of the outer ring of wires. In the new ropes the outer rings of the strands are each composed of two different diameters of wires (see Table I) which are placed alternately in the ring. This renders the envelope of the strand more nearly cylindrical. In the case of the worn rope this approximately cylindrical shape is obtained by the use of filler wires. The wires composing the core and the middle ring, on the other hand, are of approximately the same diameter. 


\section{DESCRIPTION OF THE TESTS.}

The tests were made on the individual wires, on the straight ropes, and on the ropes on sheaves of different diameters. All of the tests were made in duplicate. The results of the duplicate tests agree almost exactly, excepting for a few tests of the worn rope.

\section{INDIVIDUAL WIRES.}

The tensile tests of the wires were made in a hand-power Olsen testing machine having a capacity of 10,000 pounds. It was decided to straighten all the wires for the sake of uniformity, as tests showed that this did not affect the results appreciably. The wires were straightened on a block of wood with light blows of a hammer.

\section{STRAIGHT ROPES.}

The samples of rope selected for test were about 6 feet long. They were tested in an Olsen four-screw vertical testing machine of 600,000 pounds capacity. (See Fig. 2.) Ordinary commercial sockets were used to hold the specimens in the testing machine. The small diameter of the sockets was one-eighth inch larger than the diameters of the ropes on which they were placed. The core was removed from the portion of the rope in the socket. After the wires had been thoroughly cleaned a small hook was formed at the end of each of the wires, and, after drawing the wires back into the socket, the socket was filled with molten zinc. It is believed that the hooks in the wires increased the bond.

To find the effect of the working load upon the rope (taken as approximately one-fifth of the ultimate strength), this load was applied and removed three times; then successive load increments were applied and entirely removed. The machine was stopped while measurements were taken, but stopping the machine or imposing repeated loads did not noticeably affect the maximum load, since in several cases this was verified by breaking an extra specimen on which the loads were not repeated.

In the second series of tests the first applied load was about one-thirtieth of the maximum load. This load and the successive increments of load were applied only once and entirely removed each time. An extensometer could not be used to measure the elongation of the rope because of the rotation of the rope as the load was applied. Direct measurements of elongations were made between two brass rings approximately 50 inches apart, attached to the rope as shown in Figure 2. These were held in place by 
Technologic Papers of the Bureau of Standards, Vol. 17

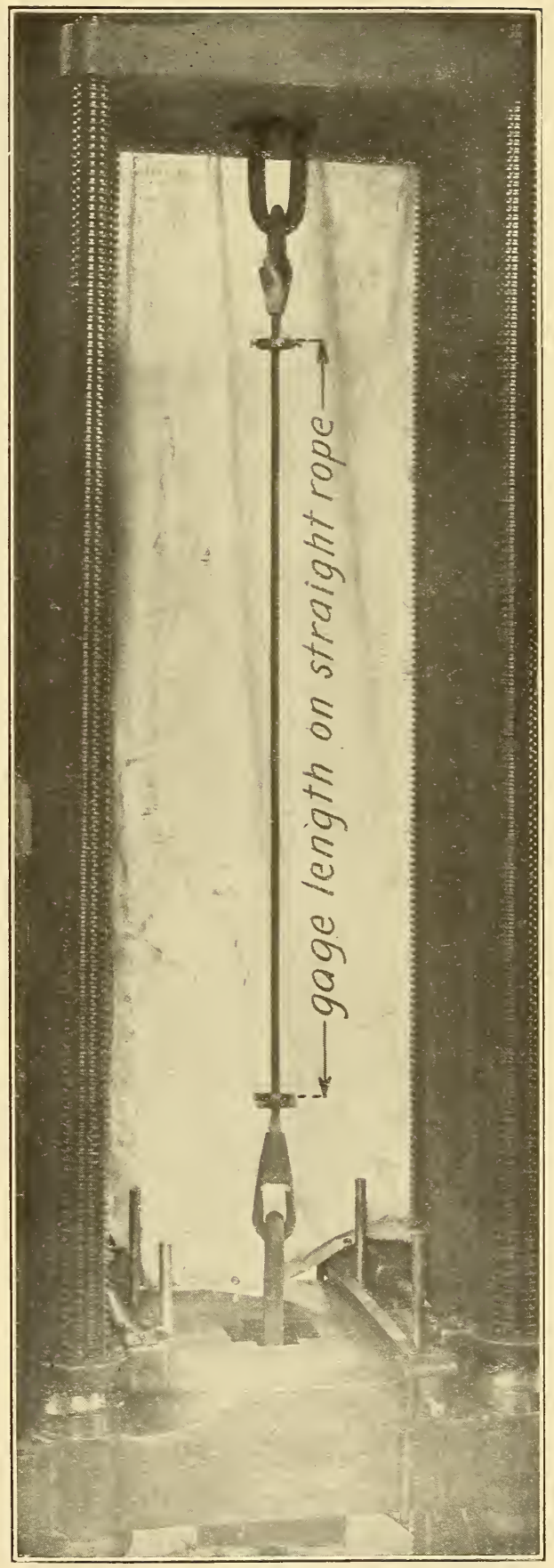

FIG. 2.-The straight rope ready for test 
Technologic Papers of the Bureau of Standards, Vol. 17

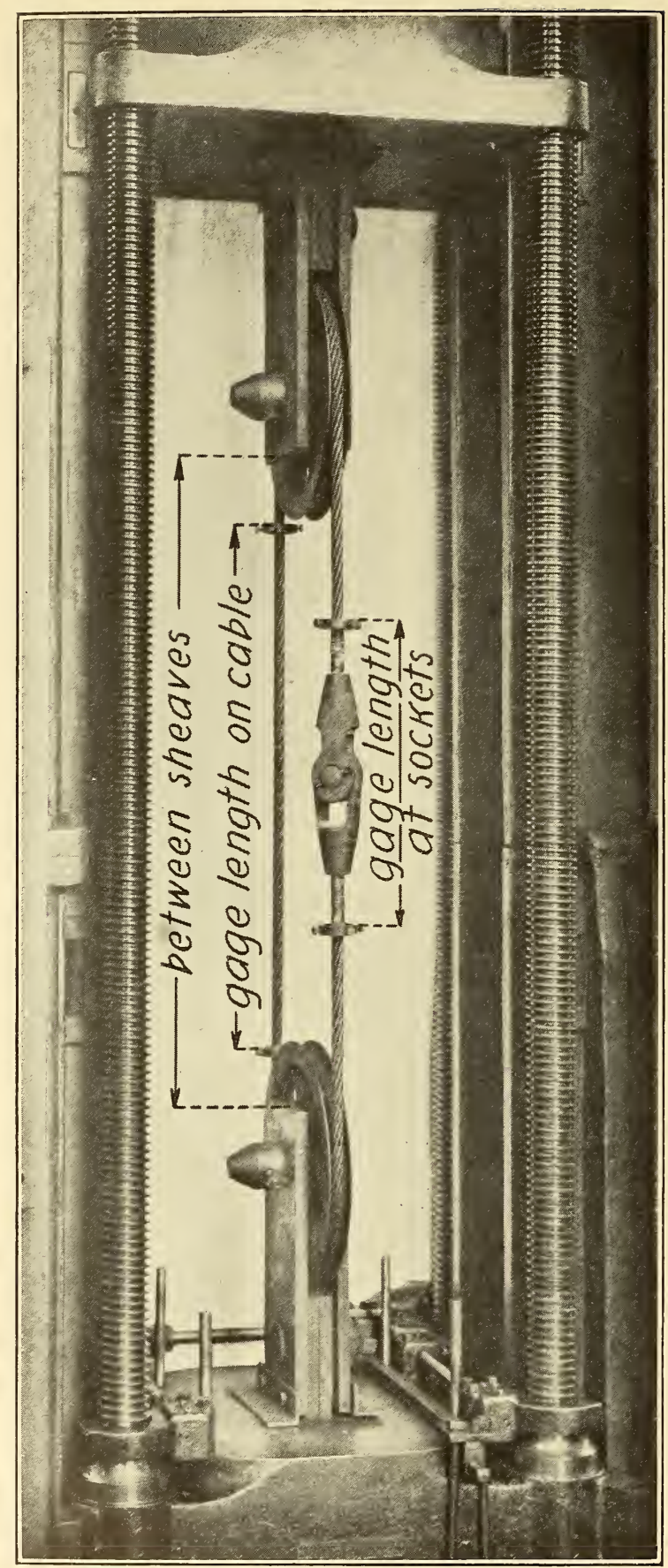

FIG. 3.-Rope on the sheaves ready for test 
Technologic Papers of the Bureau of Standards, Vol. 17

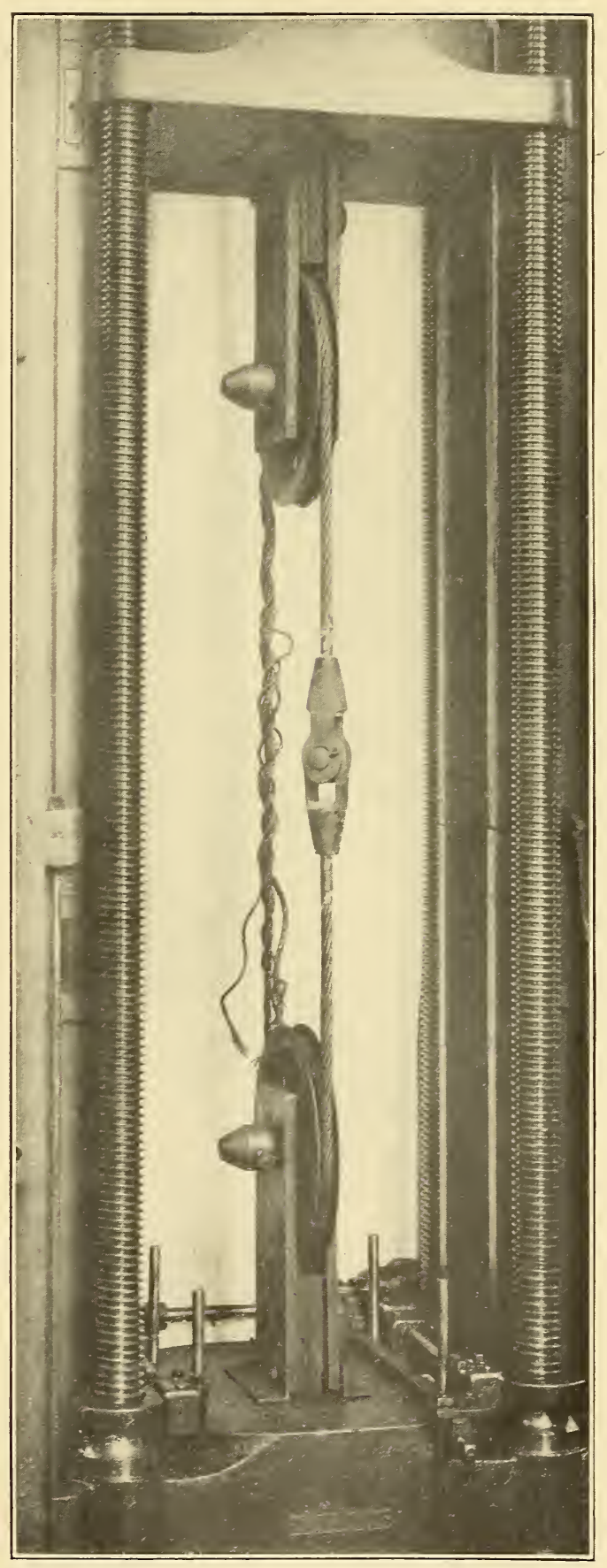

FIG. 4.-Rope on the sheaves after test 
Technologic Papers of the Bureau of Standards, Vol. 17

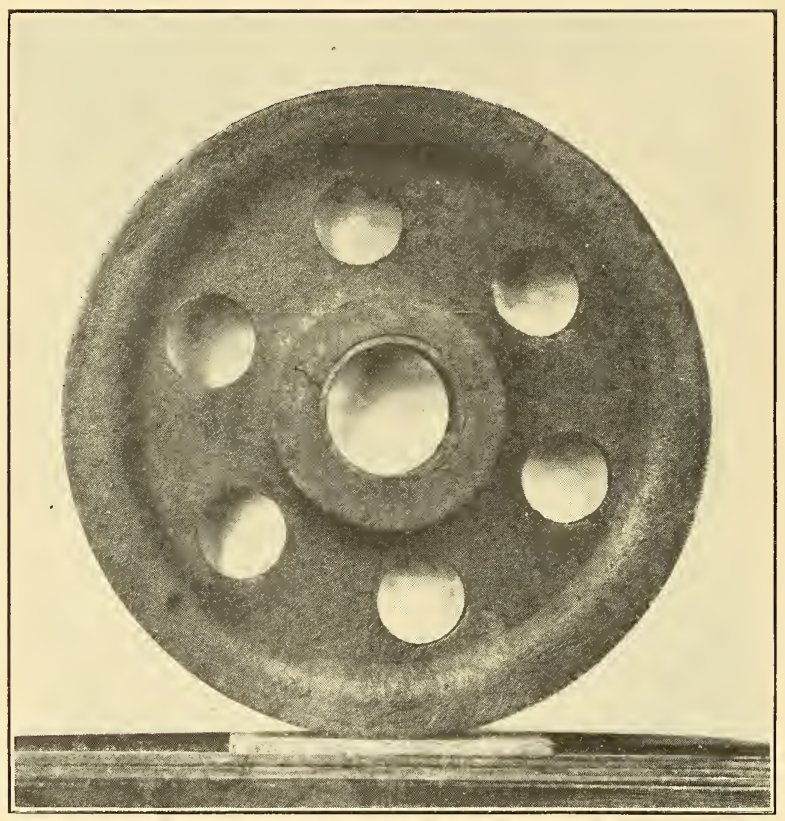

Fig. 5.-Characteristic failure of a cast-iron sheave

The large size ropes had been tested on cast-steel sheaves 
four set screws which pressed firmly upon a small strip of rubber gasket wrapped around the rope. The distance between the rings was measured to the nearest 0.01 inch with a steel scale at three equidistant points on the circumference. The average difference of these readings was taken as the elongation. The diameter of the ropes was measured with a micrometer caliper and the readings were always the largest diameter at a marked place near the midlength of the specimen.

\section{ROPES ON SHEAVES.}

The pieces of rope tested on sheaves were about 12 feet long, with an open socket on one end and a closed one on the other. After placing the rope around the two sheaves the sockets were fastened together. One of the sheaves was supported by the fixed head of the testing machine, the other was fastened to the movable head, and the load applied to the rope by pulling the sheaves apart. The arrangement is shown in Figure 3, while Figure 4 shows the rope after it had been broken.

The relative displacement of the sheaves was determined by measuring the distance between the straps holding the two sheaves, while the elongation of the straight rope was measured between brass rings, as shown in Figure 3. Before the first test on sheaves was made it was thought that the elongation of the sockets might be so great that there would be a tendency for the sheaves to turn and equalize the tensions. In order to determine whether the resistance of the sheaves to turning would be enough to influence the elongation of the rope on the two sides, a test was made in which measurements were taken on both sides. After correcting for the deformation of the sockets the unit elongation of the rope was found to be so nearly the same on both sides of the sheaves that in all other tests the elongation was measured on one side only.

The wires of the "worn" rope, including those of the rope core, showed a lack of lubrication, which probably accounted for the great wear. The construction of the new ropes of the same size was slightly different from that of the worn one, yet other tests show that the strengths of the two samples should have been practically the same when they were new.

Trouble was experienced with breaking of the sheaves, particularly when testing the I-inch rope, for which cast-steel sheaves had to be obtained. At first cast-iron sheaves having thin webs were used. One of these, showing a characteristic failure, is shown in Figure 5 . 


\section{RESULTS OF THE TESTS.}

\section{INDIVIDUAL WIRES.}

The summary of the results of the tests of individual wires is found in Table I. All the wires tested, except the filler wires in the worn rope, showed a high unit strength averaging 230,000 lbs./in. ${ }^{2}$ The average of the maximum deviations from the average tensile strength for every size of wire is about ro per cent. There is no apparent variation of the tensile properties of the wires with the diameter. The wires showed no sign of failure until the maximum load was approached, when the local elonga-

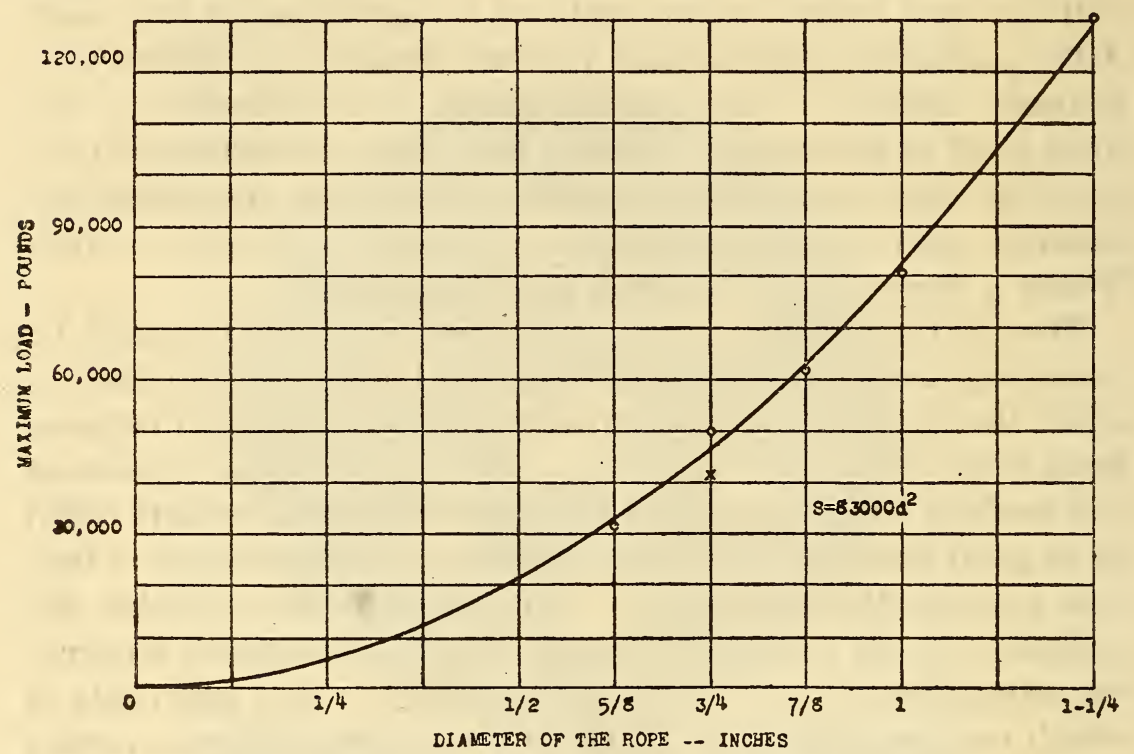

FIG. 6.-The tensile strength of straight new rope.

tion and necking began, which was quickly followed by rupture. The strength of a wire was greatly decreased by a spot of rust, a small cut, or by a worn place. The results of tensile tests of individual wires agree with those of the previous tests made by this bureau and reported in its Technologic Paper No. I2I.

\section{STRAIGHT ROPES.}

The data obtained from the testing of ropes are given in Tables 2 and 3 , and Figure 6 . The tensile strength of these ropes follows closely the equation $S=83,000 d^{2}$, (see Fig. 6), where $S$ is tensile strength in pounds and $d$ the diameter of the rope in inches.

Figures 7 to ro show the unit elongation and the reduction of diameter of the rope under repeated loads. As previously stated, 


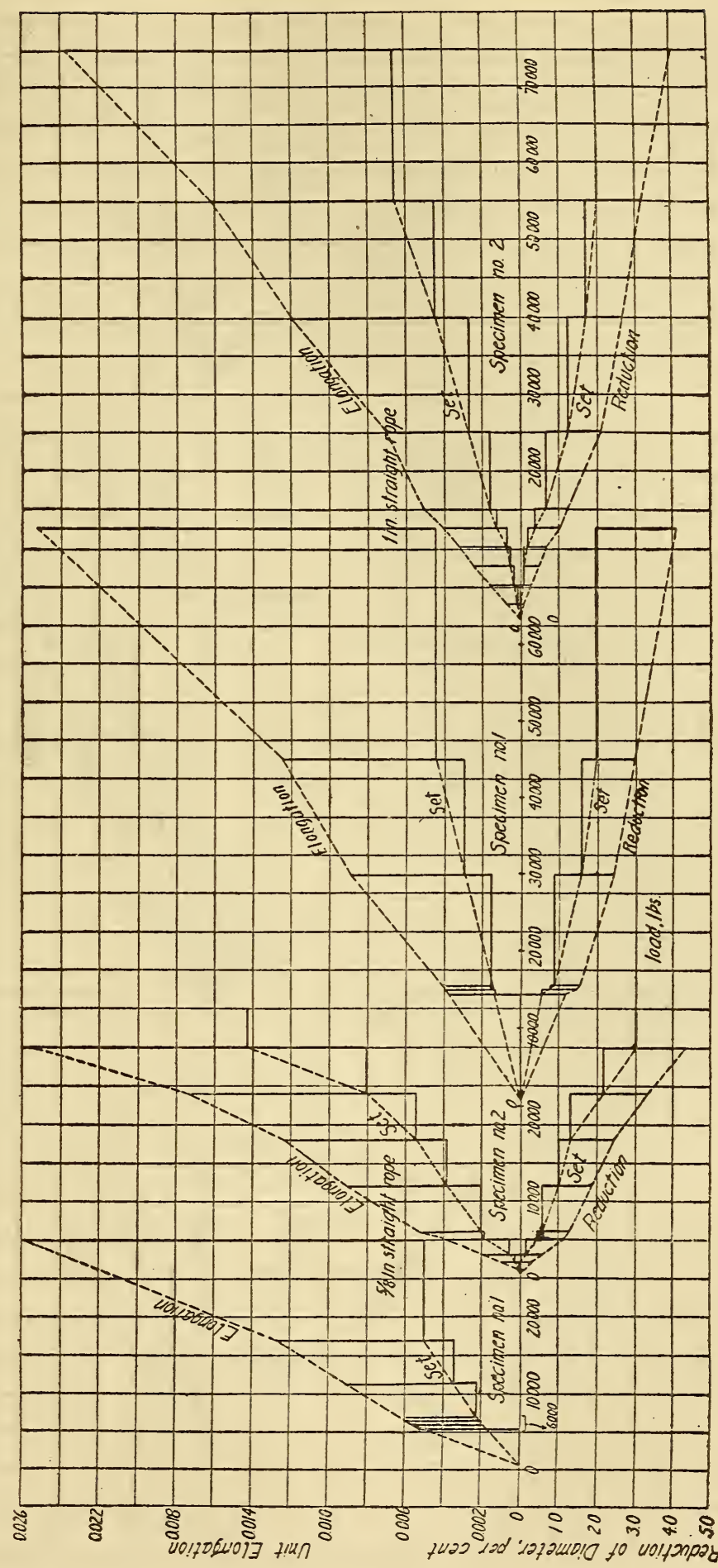




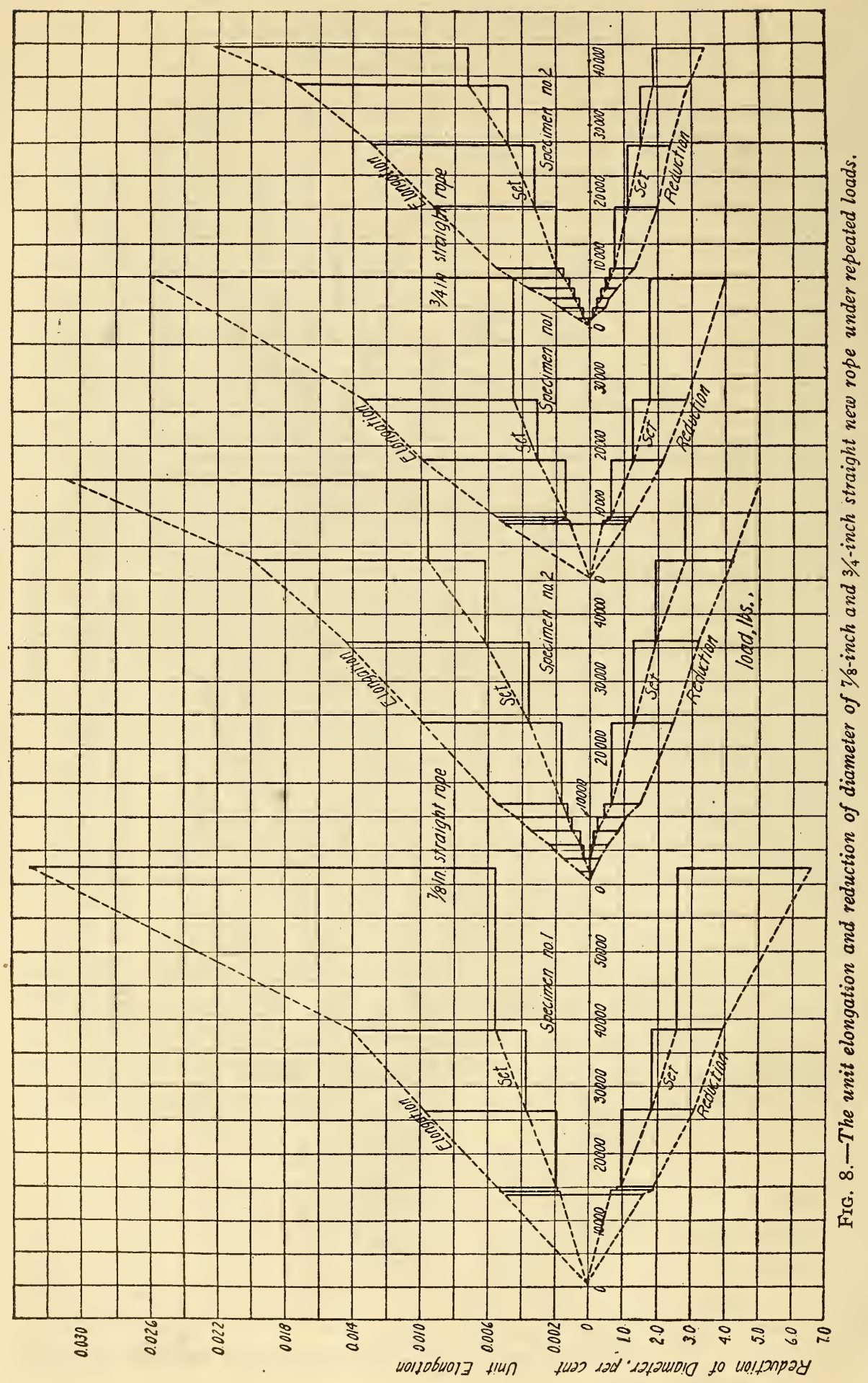




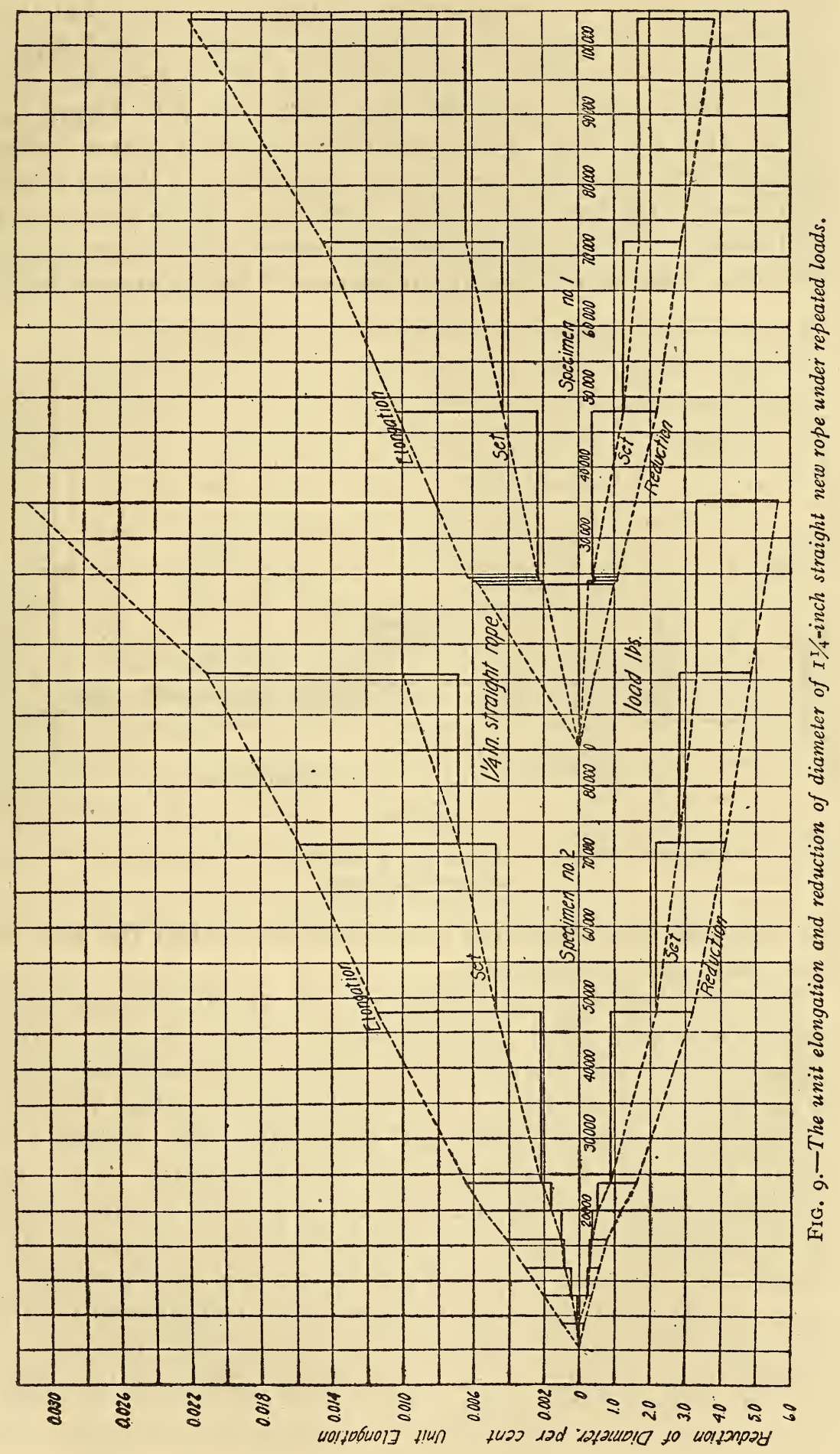


[Vol. $x 7$

repeated loads did not seem to alter the maximum loads, but this is not true of the elongation. Comparing Figure 8 ( $7 / 8$-inch rope), which may be considered as representative of the behavior of a straight rope under continuously increasing load, with Figure I4, we see that the slope of the load-unit elongation curves under repeated and increasing loads is not constant as in Figure 8 but changes with the increase of load. Comparison of the data shown in Figure 8 with those for straight ropes under continuously increasing loads shows that the repetition of load is accompanied

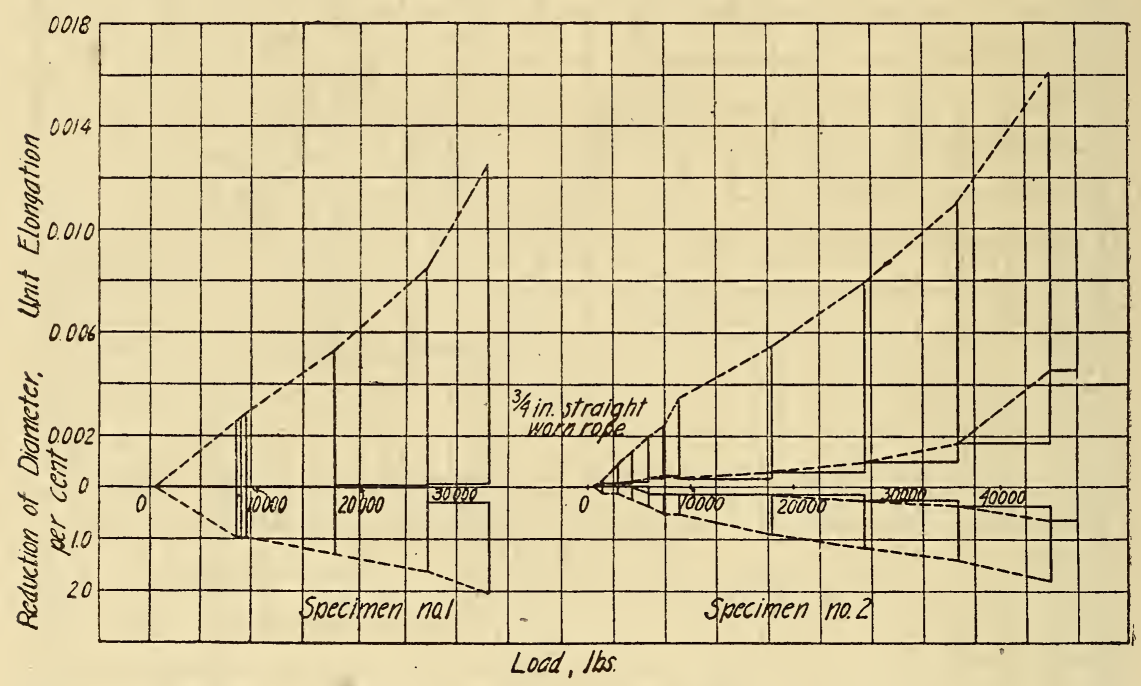

FIG. Ic.-The unit elongation and reduction of diameter of 3/4-inch straight worn rope under repeated loads.

by a greater unit elongation than in the case when the load is being increased continuously.

From the examination of Figures 7 to Io the following phenomena may be noticed: Under repeated loading the rate of the change of unit elongation and of the reduction of diameter decreases as the load is increased up to a certain load, above which the rate of elongation again increases and, apparently, more rapidly the greater the load. It seems probable that this change of rate of elongation, represented by the inflection in the load diagram, may be of importance in selecting a working load for wire rope. Although the permanent set below this inflection is due to readjustment of individual wires and strands and to compression of the rope core, with loss of lubricant, that beyond this inflection is probably due, in part, to set in the wires. Owing to the large 
load increments near the inflection, the latter can not be determined very accurately from the curves. However, the apparent values are given in Table 2. It is never below 56 per cent of the ultimate strength, and approaches probably 65 per cent, as some of the individual curves show. The "inflection" of $3 / 4$-inch worn rope is 73 per cent. Assuming the working load of a straight rope as one-fifth of its ultimate strength, we find the average elongation and set after several applications of this load, which are given in Table 3 .

Most of the set, in both the length and the diameter of the rope, is probably due to the fact that, as the load is applied, especially if it is high, the rope core is compressed and large quantities of lubricant are squeezed out. When the load is removed this

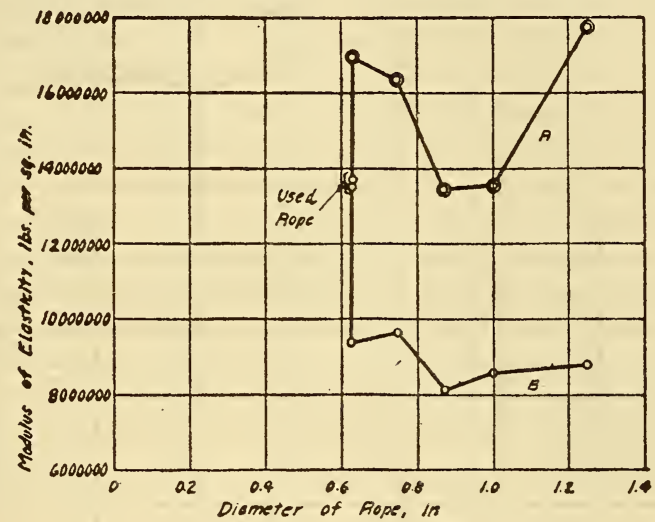

FIG. II.-Modulus of elasticity of rope.

$A$, the modulus estimated from the total elongation; $B$, the modulus estimated from the elastic elongation only.

lubricant remains on the wires and is lost. After the rope is broken the core is very compact, most of the lubricant having been squeezed out. This indicates that for given conditions the internal wear on a hoisting rope would be very much greater after an unusually heavy load had been applied, even if only once, since the one heavy load would squeeze out more of the lubricant from the interior of the rope than the working load applied many times. This lubricant can not be easily replaced. Under the ordinary working load the lubricant would be squeezed out very slowly even if the load were repeated many times.

As the elongation varies greatly under different loading conditions, the apparent modulus of elasticity of the rope will depend upon the value of the load which is chosen for computing it. In this discussion the modulus of elasticity was determined from 
load-elongation diagrams for repeated loading (specimen No. I for each size, Figs. 7 to Io). That portion of the diagram which lies immediately above the working load and below the inflection point was used. The lower portion of the diagram (below working load) was omitted, as it contains the effect of initial bends which were eliminated by loading the rope repeatedly up to the working load.

In Figure I I are given two curves. One of them represents the values of the modulus of elasticity, estimated on the basis of the

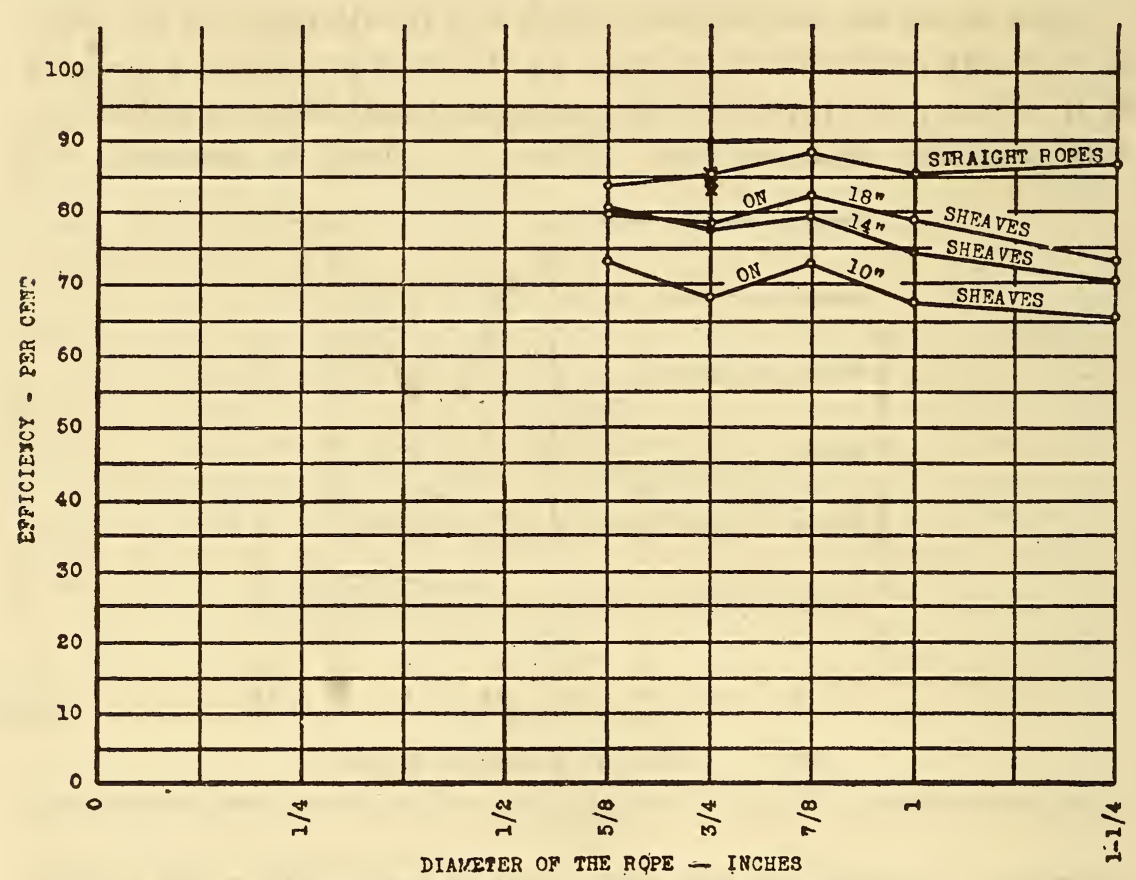

FrG. 12.-The efficiency of the steel in the straight ropes.

total elongation (elastic plus permanent set), and the other on the basis of elastic elongation only.

The diameter of the rope as well as its length changes when loads are applied. It will be seen from Figures 7 to ro that these changes are, in a general way, proportional to the changes in length, but that for repeated equal loads the diameter changes more, proportionally, than the length. Part of this change seems to be permanent.

The efficiency of the steel in the straight ropes is shown in Figure I 2. It is about 85 per cent and seems to be independent of the size of the rope. 


\section{ROPES ON SHEAVES.}

The results of tests on sheaves are found in Table 4. In every case the strength of a rope over sheaves was lower than that found for the straight rope. The strength decreased progressively as the diameter of the sheave was reduced.

The efficiencies or ratios of the strength on sheaves to the strength in tensile test are given in Figure I3, where it can be seen

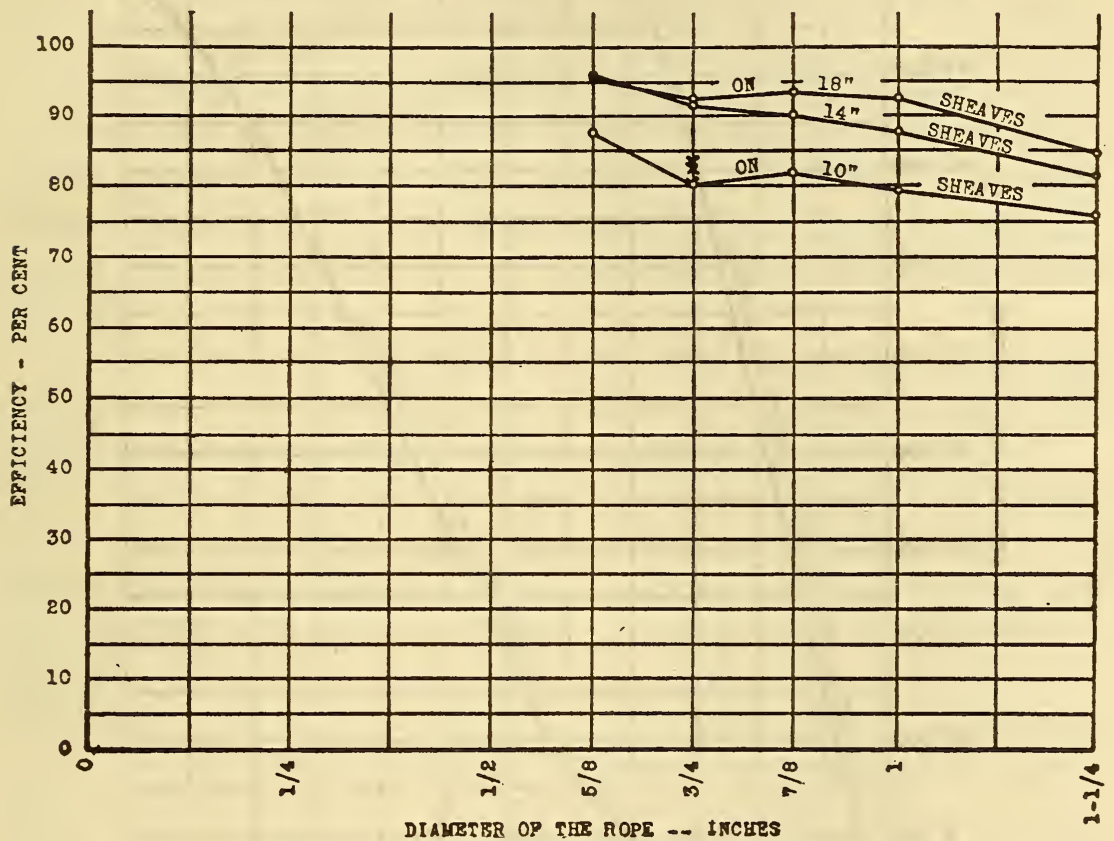

Fig. 13. - The efficiency of the rope on sheaves.

that the lowest efficiency, that for the $1 / 4$-inch rope over Io-inch sheave, was only 76 per cent.

The action of the ropes under load is shown in Figure I4. Only typical curves are shown, since the others, if plotted, would be more or less similar. The elongation of that portion of the rope which was in contact with the sheaves was found as the difference between twice the change of the distance between the sheaves and the elongation of the straight portion of the rope (including the sockets).

The elongation of the rope under repeated loads and the variation of the diameter with the load were determined by tests of straight ropes, so it was thought unnecessary to repeat these tests when the rope was on sheaves. The elongation was measured in 
both series of tests, but a longer gage length was used on the straight ropes. In some cases low loads did not straighten the part of the rope between the sheaves, so that the elongation may appear to be greater at the beginning of each test. This applies especially to the largest ropes when tested on the smallest sheaves.

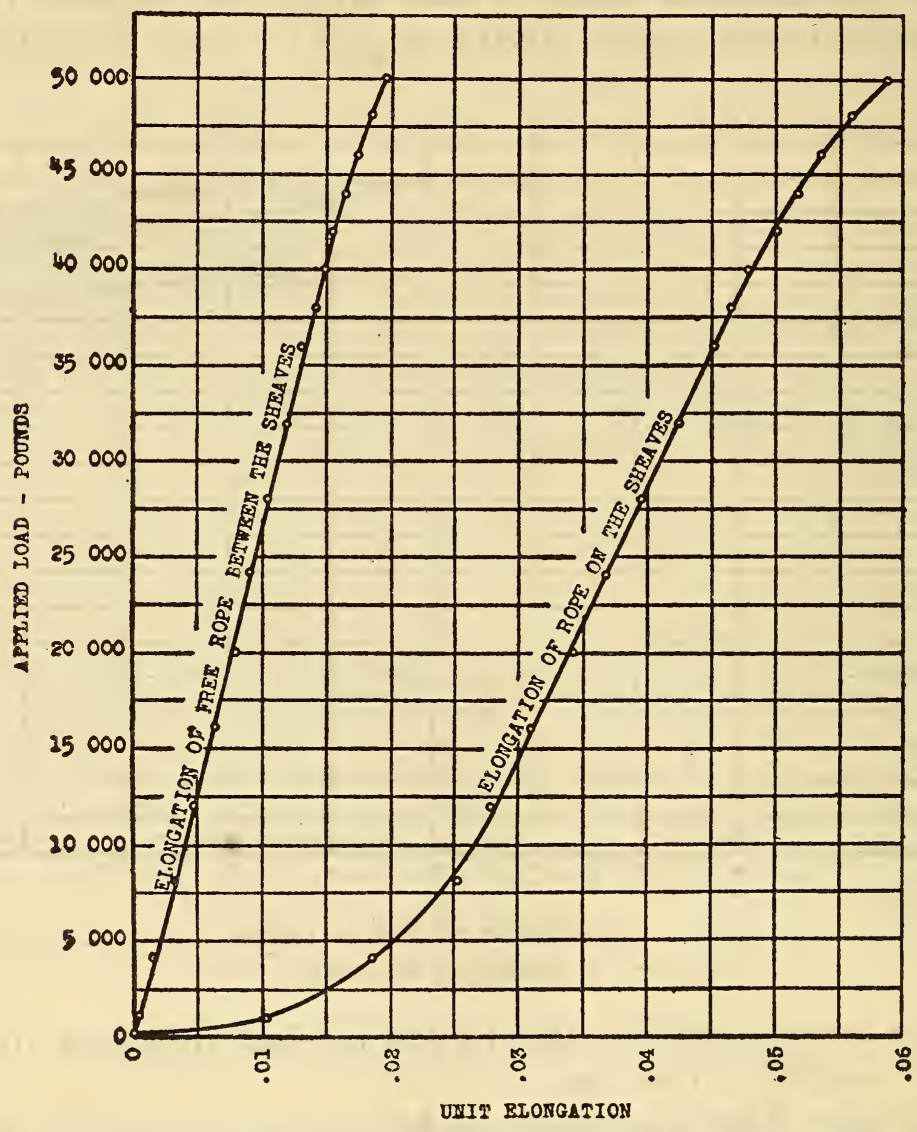

FIG. I4.-The elongation of straight rope and of the rope on sheaves.

Almost all of the ropes broke at the point where the rope leaves the sheave.

\section{CONCLUSIONS.}

I. The wires of the new ropes showed high tensile strength, averaging about $230,000 \mathrm{lbs}$./in. ${ }^{2}$ The average elongation of the wires was about 2 per cent and the reduction of area about 46 per cent. The tensile properties of individual wires within the limits of tests do not vary appreciably with the diameter of the wire.

2. The efficiency of the steel in a straight rope was about 85 per cent and seems to be independent of the diameter of the rope. 
3. The tensile strength of the straight ropes follows closely the equation $\mathrm{S}=83,000 d^{2}$ pounds, where $S$ is the strength and $d$ is the diameter of the rope in inches.

4. The load sustained by the worn rope was surprisingly high when it is known that all the outside wires were worn and some of them were broken. Tests showed that the inside wires were practically as strong as new ones of the same diameter, while the outside wires were not so strong, and always broke at worn or rusty places. This shows that a worn rope may be much stronger than might be judged from its appearance and may give satisfactory service. A worn rope should, of course, never be used, if danger to life or great property damage might result from its failure. In every case a rigid inspection should be made at regular intervals wherever ropes are in daily use or are subjected to severe intermittent service.

5. The point of inflection in the load diagram for straight rope may be assumed at two-thirds its ultimate strength for new ropes and probably increases a little with service.

6. Under tensile loads a rope undergoes considerable elongation and reduction of diameter. The total elongation when near the breaking load was about 2.5 per cent under the conditions of the test with repeated loads. A rope may be expected to stretch appreciably even with low loads. The percentage of reduction of diameter is higher than the percentage of elongation.

7. The modulus of elasticity of a steel-wire rope may be assumed to be about $8,500,000 \mathrm{lbs}$./in. ${ }^{2}$ for new ropes subjected for a number of times to the repeated loads of about one-fifth their ultimate strengths.

8. Two lines of rope over a sheave are not twice as strong as a straight rope, and the strength decreases rapidly as the diameter of the sheave decreases. The highest stress in the rope on a sheave is probably at the point where it leaves the sheave. This is true only when the load is applied without moving the sheaves after the rope is placed upon them, for it seems possible that, if the sheaves were turning, the same stress might exist in the rope wherever it touched the sheaves, since it would then be laid on them at a uniform tension as they turned. In these tests the loads were applied without turning the sheaves after the rope had been put in place.

9. All the results obtained on the straight ropes and individual wires are in reasonable agreement with the results previously obtained by the bureau and reported in Technologic Paper No. I2I. 
TABLE 1.-Tensile Tests of Plow Steel Wires Selected from 6 by 19 Ropes of Different Diameters.

\begin{tabular}{|c|c|c|c|c|c|}
\hline Diameter of rope (inches.) & $\begin{array}{l}\text { Diameter } \\
\text { of wire. }\end{array}$ & Location of wire. & $\begin{array}{l}\text { Tensile } \\
\text { strength. }\end{array}$ & $\begin{array}{l}\text { Elongation } \\
\text { in } 8 \text { inches. }\end{array}$ & $\begin{array}{l}\text { Reduction } \\
\text { of area. }\end{array}$ \\
\hline $5, \ldots \ldots \ldots \ldots$ & $\begin{array}{r}\text { Inch. } \\
0.047 \\
.050 \\
.036\end{array}$ & 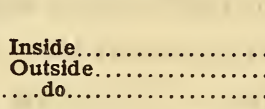 & $\begin{array}{r}\text { Lbs./in. }^{2} \\
221,600 \\
215,750 \\
211,600\end{array}$ & $\begin{array}{r}\text { Per cent. } \\
1.82 \\
1.86 \\
2.15\end{array}$ & $\begin{array}{r}\text { Per cent. } \\
50.5 \\
52.5 \\
52.5\end{array}$ \\
\hline $8 / 4 \ldots \ldots \ldots \ldots, \ldots, \cdots \cdots \cdots$, & $\begin{array}{l}.054 \\
.058 \\
.042\end{array}$ & 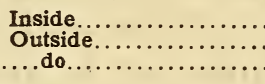 & $\begin{array}{l}253,500 \\
216,300 \\
285,100\end{array}$ & $\begin{array}{l}1.85 \\
2.47 \\
1.50\end{array}$ & $\begin{array}{l}45.5 \\
43.5 \\
46.0\end{array}$ \\
\hline $7 / 8 \ldots \ldots$ & $\begin{array}{l}.063 \\
.065 \\
.049\end{array}$ & 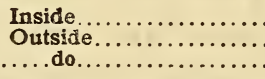 & $\begin{array}{l}219,700 \\
225,800 \\
217,800\end{array}$ & $\begin{array}{l}2.02 \\
1.96 \\
1.71\end{array}$ & $\begin{array}{l}48.0 \\
47.5 \\
50.0\end{array}$ \\
\hline $1 \ldots \ldots \ldots \ldots$ & $\begin{array}{l}.071 \\
.075 \\
.056\end{array}$ & $\begin{array}{l}\text { Inside } \ldots . . . \ldots \\
\text { Outside......... } \\
\ldots \ldots \text { do } \ldots \ldots \ldots\end{array}$ & $\begin{array}{l}239,000 \\
232,900 \\
224,800\end{array}$ & $\begin{array}{l}1.82 \\
2.20 \\
1.66\end{array}$ & $\begin{array}{l}47.0 \\
45.5 \\
49.5\end{array}$ \\
\hline $11 / 4 \ldots \ldots \ldots \ldots$ & $\begin{array}{l}.091 \\
.094 \\
.070\end{array}$ & $\begin{array}{l}\text { Inside } \ldots . . . \\
\text { Outside... } \\
\ldots \ldots \text { do } \ldots \ldots\end{array}$ & $\begin{array}{l}237,700 \\
219,800 \\
228,700\end{array}$ & $\begin{array}{l}2.21 \\
2.38 \\
1.86\end{array}$ & $\begin{array}{l}44.0 \\
41.5 \\
49.0\end{array}$ \\
\hline Average.. & & & 230,000 & 1.96 & 46.2 \\
\hline $3 / 4$ (worn rope). & $\begin{array}{l}.052 \\
.050 \\
.019\end{array}$ & $\begin{array}{l}\text { Inside..... } \\
\text { Outside... } \\
\text { Filler.... }\end{array}$ & $\begin{array}{r}202,600 \\
160,300 \\
70,200\end{array}$ & $\begin{array}{l}1.60 \\
.55 \\
3.11\end{array}$ & $\begin{array}{l}47.5 \\
28.5 \\
40.5\end{array}$ \\
\hline
\end{tabular}

NoTE.-(I) The averages given above are those of $\mathrm{I} 2$ observations each, except for filler wire in worn rope, in which case the number of observations was $6 ;(2)$ With few exceptions the fractures were half cups.

TABLE 2.-Tensile Tests of Straight Ropes.

\begin{tabular}{|c|c|c|c|c|c|}
\hline $\begin{array}{l}\text { Diameter of rope } \\
\text { (inches). }\end{array}$ & $\begin{array}{l}\text { Load at } \\
\text { inflection } \\
\text { point on } \\
\text { load- } \\
\text { elongation } \\
\text { diagram. }\end{array}$ & $\begin{array}{l}\text { Ultimate } \\
\text { strength. }\end{array}$ & $\begin{array}{l}\text { Diameter of rope } \\
\text { (inches). }\end{array}$ & $\begin{array}{l}\text { Load at } \\
\text { inflection } \\
\text { point on } \\
\text { load- } \\
\text { elongation } \\
\text { diagram. }\end{array}$ & $\begin{array}{l}\text { Ultimate } \\
\text { strength. }\end{array}$ \\
\hline \multirow{3}{*}{ Average........... } & $\begin{array}{r}\text { Pounds. } \\
17,000 \\
18,000\end{array}$ & $\begin{array}{r}\text { Pounds. } \\
32,150 \\
32,310\end{array}$ & \multirow{6}{*}{ Average......... } & $\begin{array}{r}\text { Pounds. } \\
45,000 \\
55,000\end{array}$ & $\begin{array}{r}\text { Pounds. } \\
82,700 \\
81,250\end{array}$ \\
\hline & 17,500 & 32,230 & & 50,000 & 81,980 \\
\hline & $\begin{array}{l}27,000 \\
27,000\end{array}$ & $\begin{array}{l}50,900 \\
48,450\end{array}$ & & $\begin{array}{l}72,000 \\
96,000\end{array}$ & $\begin{array}{l}130,450 \\
130,860\end{array}$ \\
\hline \multirow[t]{2}{*}{ Average.......... } & 27,000 & 49,680 & & 84,000 & 130,660 \\
\hline & $\begin{array}{l}36,000 \\
36,000\end{array}$ & $\begin{array}{l}62,900 \\
62,800\end{array}$ & & $\begin{array}{l}27,000 \\
36,000\end{array}$ & $\begin{array}{l}35,740 \\
50,060\end{array}$ \\
\hline Average............ & 36,000 & 62,850 & & 31,500 & 42,900 \\
\hline
\end{tabular}

TABLE 3.-Elongation and Permanent Set of a Straight Rope under Working Load.

\begin{tabular}{|c|c|c|c|c|c|c|c|}
\hline $\begin{array}{l}\text { Diameter of rope } \\
\text { (inches). }\end{array}$ & $\begin{array}{l}\text { Working } \\
\text { load. }\end{array}$ & $\begin{array}{c}\text { Elonga- } \\
\text { tion. }\end{array}$ & $\begin{array}{l}\text { Perma- } \\
\text { nent set. }\end{array}$ & $\begin{array}{l}\text { Diameter of rope } \\
\text { (inches). }\end{array}$ & $\begin{array}{l}\text { Working } \\
\text { load. }\end{array}$ & $\begin{array}{c}\text { Elonga- } \\
\text { tion. }\end{array}$ & $\begin{array}{l}\text { Perma- } \\
\text { nent set. }\end{array}$ \\
\hline 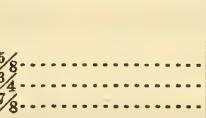 & $\begin{array}{r}\text { Pounds. } \\
6,450 \\
9,940 \\
12,570\end{array}$ & $\begin{array}{r}\text { Inches } \\
\text { per inch. } \\
0.0057 \\
.0058 \\
.0055\end{array}$ & $\begin{array}{r}\text { Inches } \\
\text { per inch. } \\
0.0020 \\
.0018 \\
.0018\end{array}$ & $11 / 4 \ldots \ldots \ldots$ & $\begin{array}{r}\text { Pounds. } \\
16,400 \\
26,130 \\
8,580\end{array}$ & 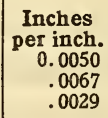 & $\begin{array}{r}\text { Inches } \\
\text { per inch. } \\
0.0017 \\
.0024 \\
.0001\end{array}$ \\
\hline
\end{tabular}


TABLE 4.-Strength of Ropes on Sheaves.

\begin{tabular}{|c|c|c|c|c|c|c|}
\hline \multirow[b]{3}{*}{ Diameter of rope (inches). } & \multicolumn{6}{|c|}{ Diameter of sheave (inches). } \\
\hline & \multicolumn{2}{|c|}{10} & \multicolumn{2}{|c|}{14} & \multicolumn{2}{|c|}{18} \\
\hline & $\begin{array}{l}\text { Oltimate } \\
\text { strength. }\end{array}$ & $\begin{array}{c}\text { Ratio of } \\
\text { ultimate } \\
\text { strength } \\
\text { to that of } \\
\text { straight } \\
\text { rope. }\end{array}$ & $\begin{array}{l}\text { Ultimate } \\
\text { strength. }\end{array}$ & $\begin{array}{l}\text { Ratio of } \\
\text { ultimate } \\
\text { strength } \\
\text { to that of } \\
\text { straight } \\
\text { rope. }\end{array}$ & $\begin{array}{l}\text { Ultimate } \\
\text { strength. }\end{array}$ & $\begin{array}{c}\text { Ratio of } \\
\text { ultimate } \\
\text { strength } \\
\text { to that of } \\
\text { straight } \\
\text { rope. }\end{array}$ \\
\hline 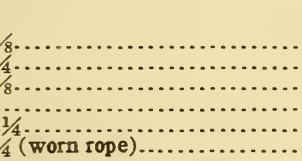 & $\begin{array}{r}\text { Pounds. } \\
28,170 \\
39,840 \\
51,470 \\
65,000 \\
99,070 \\
35,830\end{array}$ & $\begin{array}{r}\text { Per cent. } \\
87.4 \\
80.3 \\
81.9 \\
79.3 \\
75.8 \\
83.5\end{array}$ & $\begin{array}{r}\text { Pounds. } \\
39,910 \\
45,350 \\
56,300 \\
71,670 \\
106,320 \\
35,300\end{array}$ & $\begin{array}{r}\text { Per cent. } \\
96.0 \\
91.5 \\
89.5 \\
87.5 \\
81.3 \\
82.3\end{array}$ & $\begin{array}{r}\text { Pounds. } \\
30,700 \\
45,840 \\
58,390 \\
75,780 \\
110,630 \\
34,700\end{array}$ & $\begin{array}{r}\text { Per cent. } \\
95.3 \\
92.5 \\
92.9 \\
92.5 \\
84.7 \\
80.9\end{array}$ \\
\hline
\end{tabular}

Washington, December 22, 1922. 